\title{
Interdependence of International Tourism Demand and Volatility in Leading ASEAN Destinations*
}

\author{
Chia-Ling Chang \\ Department of Applied Economics \\ National Chung Hsing University \\ Taichung, Taiwan \\ Thanchanok Khamkaew \\ Faculty of Economics \\ Maejo University \\ Chiang Mai, Thailand \\ Michael McAleer \\ Econometric Institute \\ Erasmus School of Economics \\ Erasmus University Rotterdam \\ and \\ Tinbergen Institute \\ The Netherlands \\ and \\ Center for International Research on the Japanese Economy (CIRJE) \\ Faculty of Economics \\ University of Tokyo \\ Roengchai Tansuchat \\ Faculty of Economics \\ Maejo University \\ Chiang Mai, Thailand
}

EI2009-36

November 2009

* The first author is most grateful to the National Science Council, Taiwan, the second and fourth authors would like to acknowledge the Faculty of Economics at Maejo University, and the third author wishes to thank the Australian Research Council and National Science Council, Taiwan. 


\begin{abstract}
International and domestic tourism are leading economic activities in the world today. Tourism has been known to generate goods and services directly and indirectly, attract foreign currency, stimulate employment, and provide opportunities for investment. It has also been recognized as an important means for achieving economic development. Substantial research has been conducted to evaluate the role of international tourism, and its associated volatility, within and across various economies. This paper applies several recently developed models of multivariate conditional volatility to investigate the interdependence of international tourism demand, as measured by international tourist arrivals, and its associated volatility in the four leading destinations in ASEAN, namely Indonesia, Malaysia, Singapore and Thailand. Each of these countries has attractive tourism characteristics, such as significant cultural and natural resources. Shocks to international tourism demand volatility could affect, positively or negatively, the volatility in tourism demand of neighbouring countries. The empirical results should encourage regional co-operation in tourism development among ASEAN member countries, and also mobilize international and regional organizations to provide appropriate policy actions.
\end{abstract}

Keywords: Tourism demand, ASEAN, multivariate GARCH, volatility spillovers, interdependence, economic development.

JEL Classifications: C22, C32, F50, O53. 


\section{Introduction}

Over the past six decades, the substantial growth in tourism activity has clearly marked tourism as one of the most remarkably important and rapidly growing sectors in the world economy. It is presently ranked fourth after fuels, chemicals and automotive products. For many developing countries, tourism is one of the main income sources that leads to exports of goods and services, generates employment, and creates opportunities for economic development.

According to the World Tourism Organization report, international tourist arrivals have continued to grow from 438 million in 1990, to 534 million in 1995, to 684 million in 2000, reaching 922 million in 2008, with an average annual growth rate of 3.8\% between 2000 and 2008. While tourism has experienced continuous growth, it has nonetheless diversified world tourism destinations. Many new destinations have emerged alongside the traditional ones of Western Europe and North America, which are the main tourist-receiving regions. Both regions tend to have less dynamic growth in joint market shares, while Asia and the Pacific have outperformed the rest of the world in terms of an increasing share of international tourist arrivals, as well as market share of world international tourism receipts (see Table 1).

\section{[Insert Table 1 here]}

Despite the collapse of global financial markets and the subsequent recession that began in December 2007, and with much greater intensity since September 2008, international tourist arrivals in 2008 reached 922 million. This was a positive figure that had increased from 904 million in 2007, thereby representing a growth rate of $2 \%$. This overall growth had been established on the strong results in the year preceding the global economic recession. All regions had positive growth, except for Europe. Asia and the Pacific saw a significant slowdown in arrivals when figures were compared to the previous bumper years, growing at just over 1\% in 2008. The deceleration from 9.6\% in 2007 to $1.2 \%$ in 2008 can be attributed principally to a rise in the price of tourism that was caused by an increase in aviation fuel prices. Growth in receipts in Asia outpaced that of arrivals. Year-on-year growth in receipts for the region was 2.7\%, compared with 9.8\% in 2007 (ASEAN TSD (2009)). 
South-East Asia and South Asia were the strongest performing sub-regions of Asia and the Pacific, growing at 3\% and 2\%, respectively, in 2008. In South-East Asia, countries such as Indonesia (13\%), Cambodia (7\%) and Malaysia (5\%) grew at above average rates. Several Asia and Pacific sub-regions, especially in South-East Asia, are now reaping increasing benefits from tourism due to their own specific tourism resources, and an improvement in the supporting and facilitating factors of infrastructure and accommodation. The ASEAN tourism performance in 2006-2008 is given in Table 2. ASEAN attracted 61.7 million tourists in 2008 , accounting for a market share of $6.7 \%$ and average annual growth rate of $6.9 \%$.

\section{[Insert Table 2 here]}

As given in Table 2, inbound tourism to South-East Asia has been distributed to four leading destinations, namely Malaysia, Thailand, Singapore, and Indonesia. The trend of international tourist arrivals to these countries has been relatively increasing over time. In terms of NorthEast Asia, tourist arrivals to South-East Asia have accounted for over $30 \%$ of the market share in the Asia and the Pacific international tourist arrivals. In Figures 1 and 2, the intraASEAN tourism is deemed to be important as extra-ASEAN tourism in this sub-region as ASEAN member countries sustained their collaboration to increase intra-ASEAN travel and fortified the promotion of the ASEAN region as a major destination for intra-ASEAN and inter-ASEAN travel.

Sharing some similarities in climate, the archeological background and cultural influence brought from India, China, Muslim-nations and Europe have led to a unification among the nations of South-East Asia. These similarities seem to have installed an influence on both regional tourism collaboration and regional tourism competitiveness. It is interesting to explore the interdependence between tourism in ASEAN, where each country could benefit and suffer from the shocks that occur in neighbouring countries. For example, negative shocks, which may capture political instability, terrorism, violent criminal behavior, and natural disasters, generally have the potential to generate volatility in tourism demand. Examining whether the impact of shocks to tourism demand in one destination would be volatile on the demand for international tourism in neighbouring destinations is a major aspect of the paper. 


\section{[Insert Figures 1 and 2 here]}

Given the importance of understanding the dependence on tourism in ASEAN, this paper estimates the conditional variance, or volatility, of monthly international tourist arrivals to four leading South-East Asian tourism countries, namely Malaysia, Thailand, Singapore and Indonesia. The estimates provide an indication of the relationship between shocks to the growth rate of monthly international tourist arrivals in each major destination in South-East Asia through the multivariate GARCH framework. The analysis of uncertainty in monthly international tourism arrivals to these major destinations has not been empirically investigated in the tourism literature. The results indicate the existence of tourism interdependence among these countries.

The structure of the remainder of the paper is as follows. Section 2 reviews the tourism volatility research literature. Section 3 discusses the univariate and multivariate GARCH models to be estimated. Section 4 gives details of the data, descriptive statistics and unit root tests. Section 5 describes the empirical estimates and some diagnostic tests of the univariate and multivatiate models. Some concluding remarks are given in Section 5.

\section{Literature Review}

Tourism demand modelling and estimation rely heavily on secondary data. It can be divided broadly into two categories, based on non-causal time series models and causal econometric approaches. The primary difference between two is whether the forecasting model identifies any causal relationship between the tourism demand variable and its influencing factors. The focus in this paper is on time series tourism modelling, which pays particular attention to exploring the historical trends and patterns in the time series ARMA-based models comprise one of the most widely used methods in time series analysis.

A recent example based on time series methods to analyze tourism demand is Lim and McAleer (1999), who used ARIMA models to explain the non-stationary seasonally unadjusted quarterly tourist arrivals from Malaysia to Australia from 1975(1) to 1996(4). HEGY (Hylleberg, Engle, Granger, and Yoo (1990)) framework was used as a pre-test for 
seasonal unit root. The finding of seasonal unit root tests in international tourist arrivals from Malaysia shows evidence of a stochastically varying seasonal pattern. A deterministic seasonal model generated by seasonal dummy variables is likely to be a less appropriate univariate seasonal representation than the seasonally integrated process proposed by HEGY, and including deterministic seasonal dummy variables to explain seasonal patterns is likely to produce fragile results if seasonal unit roots are present. Lim and McAleer (2002) estimated Australian tourism demand from Asian source markets over the period 1975(1)-1984(4) by using various ARIMA models. As the best fitting ARIMA model is found to have the lowest RMSE, this model is used to obtain post-sample forecasts. The fitted ARIMA model forecasts tourist arrivals from Singapore for the period 1990(1)-1996(4) very well. Although the ARIMA model outperforms the seasonal ARIMA models for Hong Kong and Malaysia, the forecasts of tourist arrivals are not as accurate as in the case of Singapore.

Goh and Law (2002) introduced a multivariate SARIMA (MSARIMA) model, which includes an intervention function to capture the potential spillover effects of the parallel demand series on a particular tourism demand series. They showed that MSARIMA model significantly improved the forecasting performance of the simple SARIMA as well as other univariate time-series models. In a similar study, Du Preez and Witt (2003) investigated the intervention effects of the time series models on forecasting performance within a state space framework. It was found that the multivariate state space time series model was outperformed by the simple ARIMA model. The application of time-series method in tourism demand analysis can also be found in Lim and McAleer (2000, 2001), Cho (2001, 2003), Kulendran and Witt (2003a, 2003b), Gil-Alana et al. (2004), Coshall (2005, 2009), Gil-Alana (2005), Kulendran and Wong (2005), Oh and Morzuch (2005), Lim et al. (2008), and Chang et.al (2009).

Another extension of the time series analysis of tourism demand has been the application of the Generalized Autoregressive Conditional Heteroscadastic (GARCH) model. The GARCH model has been used widely in financial econometrics to investigate the volatility of the time series. Univariate models of volatility in tourism demand have been used in, for example, Shareef and McAleer (2005), Chang et al. (2009), Chang et al. (2009a, 2009b), McAleer et al. (2009), and Divino and McAleer (2009a, 2009b) at different time series frequencies, ranging from monthly to daily data. Although the volatility concept is becoming increasingly popular 
in tourism research, few studies have yet applied multivariate models of volatility in tourism demand. In this respect, Chan et al. (2005) applied three multivariate GARCH models to examine the volatility of tourism demand for Australia and the effect of various shocks in the tourism demand models. The results suggested the presence of interdependent effects in the conditional variances between four leading countries, namely Japan, New Zealand, UK and USA, and asymmetric effects of shocks in two of the four countries.

Shareef and McAleer (2007) examined the uncertainty in monthly international tourist arrivals to the Maldives from eight major tourist source countries, namely Italy, Germany, UK, Japan, France, Switzerland, Austria and the Netherlands, from 1 January 1994 to 31 December 2003. Univariate and multivariate time series models of conditional volatility were estimated and tested. The conditional correlations were estimated and examined to ascertain whether there is specialization, diversification or segmentation in the international tourism demand shocks from the major tourism sources countries to the Maldives. The estimated static conditional correlations for monthly international tourist arrivals, as well as for the respective transformed series, were found to be significantly different from zero, but nevertheless relatively low.

Hoti et al. (2007) compared tourism growth, country risk returns and their associated volatilities for Cyprus and Malta. Monthly data were available for both international tourist arrivals and composite country risk ratings compiled by the International Country Risk Guide (ICRG) for the period May 1986 to May 2002. The time-varying conditional variances of tourism growth and country risk returns for the two Small Island Tourism Economies (SITEs) were analyzed using multivariate models of conditional volatility. The empirical results showed that Cyprus and Malta were complementary destinations for international tourists, such that changes to tourism patterns in Cyprus led to changes in tourism patterns in Malta.

\section{Econometric methodology}

\subsubsection{Univariate Conditional Volatility Models}


Following Engle (1982), consider the time series $y_{t}=E_{t-1}\left(y_{t}\right)+\varepsilon_{t}$, where $E_{t-1}\left(y_{t}\right)$ is the conditional expectation of $y_{t}$ at time $t-1$ and $\varepsilon_{t}$ is the associated error. The generalized autoregressive conditional heteroskedastity (GARCH) model of Bollerslev (1986) is given as follows:

$$
\begin{aligned}
& \varepsilon_{t}=\sqrt{h_{t}} \eta_{t} \quad, \quad \eta_{t} \square N(0,1) \\
& h_{t}=\omega+\sum_{j=1}^{p} \alpha_{j} \varepsilon_{t-j}^{2}+\sum_{j=1}^{q} \beta_{j} h_{t-j}
\end{aligned}
$$

where $\omega>0, \alpha_{j} \geq 0$ and $\beta_{j} \geq 0$ are sufficient conditions to ensure that the conditional variance $h_{t}>0$. The parameter $\alpha_{j}$ represents the ARCH effect, or the short-run persistence of shocks to the log arrival rate, and $\beta_{j}$ represents the GARCH effect, where $\alpha_{j}+\beta_{j}$ measures the long run persistence of shocks to the log arrival rate.

Equation (2) assumes that the conditional variance is a function of the magnitudes of the lagged residuals and not their signs, such that a positive shock $\left(\varepsilon_{t}>0\right)$ has the same impact on conditional variance as a negative shock $\left(\varepsilon_{t}<0\right)$ of equal magnitude. In order to accommodate differential impacts on the conditional variance of positive and negative shocks, Glosten et al. (1993) proposed the asymmetric (or threshold) GARCH, or GJR model, which is given by

$$
h_{t}=\omega+\sum_{j=1}^{r}\left(\alpha_{j}+\gamma_{j} I\left(\varepsilon_{t-j}\right)\right) \varepsilon_{t-j}^{2}+\sum_{j=1}^{s} \beta_{j} h_{t-j}
$$

where

$$
I_{i t}= \begin{cases}0, & \varepsilon_{i t} \geq 0 \\ 1, & \varepsilon_{i t}<0\end{cases}
$$


is an indicator function to differentiate between positive and negative shocks. When $r=s=1$, sufficient conditions to ensure the conditional variance, $h_{t}>0$, are $\omega>0, \alpha_{1} \geq 0, \alpha_{1}+\gamma_{1} \geq 0$ and $\beta_{1} \geq 0$. The short run persistence of positive and negative shocks are given by $\alpha_{1}$ and $\left(\alpha_{1}+\gamma_{1}\right)$, respectively. When the conditional shocks, $\eta_{t}$, follow a symmetric distribution, the short run persistence is $\alpha_{1}+\gamma_{1} / 2$, and the contribution of shocks to expected long-run persistence is $\alpha_{1}+\gamma_{1} / 2+\beta_{1}$.

In order to estimate the parameters of model (1)-(3), maximum likelihood estimation is used with a joint normal distribution of $\eta_{t}$. However, when $\eta_{t}$ does not follow a normal distribution or the conditional distribution is not known, quasi-MLE (QMLE) is used to maximize the likelihood function.

Bollerslev (1986) showed the necessary and sufficient condition for the second-order stationarity of GARCH is $\sum_{i=1}^{r} \alpha_{i}+\sum_{i=1}^{s} \beta_{i}<1$. For the GARCH(1,1) model, Nelson (1991) obtained the log-moment condition for strict stationary and ergodicity as $E\left(\log \left(\alpha_{1} \eta_{t}^{2}\right)+\beta_{1}\right)<0$, which is important in deriving the statistical properties of the QMLE. For GJR(1,1), Ling and McAleer (2002a, 2002b) presented the necessary and sufficient condition for $E\left(\varepsilon_{t}^{2}\right)<\infty$ as $\alpha_{1}+\gamma_{1} / 2+\beta_{1}<1$. McAleer et al. (2007) established the logmoment condition for $\operatorname{GJR}(1,1)$ as $E\left(\log \left(\alpha_{1}+\gamma_{1} I\left(\eta_{t}\right) \eta_{t}^{2}+\beta_{1}\right)\right)<0$, and showed that it is sufficient for consistency and asymptotic normality of the QMLE.

In order to capture asymmetric behavior in the conditional variance with alternative model, Nelson (1991) proposed the Exponential GARCH (EGARCH) model, namely:

$$
\log h_{t}=\omega+\sum_{i=1}^{r} \alpha_{i}\left|\eta_{t-i}\right|+\sum_{i=1}^{r} \gamma_{i} \eta_{t-i}+\sum_{j=1}^{s} \beta_{j} \log h_{t-j},
$$

where $\left|\eta_{t-i}\right|$ and $\eta_{t-i}$ capture the size and sign effects of the standardized shocks, respectively. If $\gamma=0$, there is no asymmetry, while $\gamma<0$ and $\gamma<\alpha<-\gamma$ are the conditions 
for a leverage effect, whereby positive shocks decrease volatility and negative shocks increase volatility.

As noted in McAleer et al. (2007) and Chang et al. (2009b), there are some distinct differences between EGARCH and the previous two model: (1) as EGARCH uses the logarithm of conditional volatility, it is guaranteed that $h_{t}>0$, so that no restrictions are required on the parameters in (4); (2) Nelson (1991) showed that $|\beta|<1$ ensures stationarity and ergodicity for EGARCH(1,1); (iii) Shephard (1996) observed that $|\beta|<1$ is likely to be a sufficient condition for consistency of QMLE for $\operatorname{EGARCH(1,1);~(iv)~as~the~standardized~}$

residuals appear in equation (4), $|\beta|<1$ would seem to be a sufficient condition for the existence of moments; (v) in addition to being a sufficient condition for consistency, $|\beta|<1$ is also likely to be sufficient for asymptotic normality of QMLE for EGARCH (1,1); and (6) moment conditions are required for the GARCH and GJR models as they are dependent on lagged unconditional shocks, whereas EGARCH does not require moment condition to be established as it depends on lagged conditional shocks (or standardized residuals).

\subsubsection{Multivariate Conditional Volatility Model}

This section presents models of the volatility in tourism demand, namely the CCC model of Bollerslev (1990), VARMA-GARCH model of Ling and McAleer (2003), and VARMAAGARCH of McAleer et al. (2009) in order to investigate the (inter) dependence of international tourism demand and volatility in leading ASEAN destinations. The typical specifications underlying the multivariate conditional mean and conditional variance in the log arrival rate are as follows:

$$
\begin{gathered}
y_{t}=E\left(y_{t} \mid F_{t-1}\right)+\varepsilon_{t} \\
\varepsilon_{t}=D_{t} \eta_{t}
\end{gathered}
$$


where $y_{t}=\left(y_{1 t}, \ldots, y_{m t}\right)^{\prime}, \quad \eta_{t}=\left(\eta_{1 t}, \ldots, \eta_{m t}\right)^{\prime}$ is a sequence of independently and identically distributed (iid) random vectors, $F_{t}$ is the past information available to time $t$, $D_{t}=\operatorname{diag}\left(h_{1}^{1 / 2}, \ldots, h_{m}^{1 / 2}\right)$.

The constant conditional correlation (CCC) model of Bollerslev (1990) assumes that the conditional variance for each log arrival rate, $h_{i t}, i=1, . ., m$, follows a univariate GARCH process, that is

$$
h_{i t}=\omega_{i}+\sum_{j=1}^{r} \alpha_{i j} \varepsilon_{i, t-j}^{2}+\sum_{j=1}^{s} \beta_{i j} h_{i, t-j}
$$

where $\alpha_{i j}$ and $\beta_{i j}$ represents the ARCH and GARCH effects, respectively. The conditional correlation matrix of CCC is $\Gamma=E\left(\eta_{t} \eta_{t}^{\prime} \mid F_{t-1}\right)=E\left(\eta_{t} \eta^{\prime}\right)$, where $\Gamma=\left\{\rho_{i t}\right\}$ for $i, j=1, \ldots, m$. From (1), $\varepsilon_{t} \varepsilon_{t}^{\prime}=D_{t} \eta_{t} \eta^{\prime} D_{t}, D_{t}=\left(\operatorname{diag} Q_{t}\right)^{1 / 2}$, and $E\left(\varepsilon_{t} \varepsilon_{t}^{\prime} \mid F_{t-1}\right)=Q_{t}=D_{t} \Gamma D_{t}$, where $Q_{t}$ is the conditional covariance matrix. The conditional correlation matrix is defined as $\Gamma=D_{t}^{-1} Q_{t} D_{t}^{-1}$, and each conditional correlation coefficient is estimated from the standardized residuals in (5) and (6). Therefore, there is no multivariate estimation involved for CCC, except in the calculation of the conditional correlations.

It is interesting that CCC does not contain any information regarding cross-country or asymmetric effect. In order to accommodate possible interdependencies, Ling and McAleer (2003) proposed a vector autoregressive moving average (VARMA) specification of the conditional mean in (5) and the following specification for the conditional variance:

$$
H_{t}=W+\sum_{i=1}^{r} A_{i} \vec{\varepsilon}_{t-i}+\sum_{j=1}^{s} B_{j} H_{t-j}
$$

where $H_{t}=\left(h_{1 t}, \ldots, h_{m t}\right)^{\prime}, \vec{\varepsilon}=\left(\varepsilon_{1 t}^{2}, \ldots \varepsilon_{m t}^{2}\right)^{\prime}$, and $W, A_{i}$ for $i=1, . ., r$ and $B_{j}$ for $j=1, . ., s$ are $m \times m$ matrices. As in the univariate GARCH model, VARMA-GARCH assumes that negative and positive shocks have identical impacts on the conditional variance. 
In order to separate the asymmetric impacts of the positive and negative shocks, McAleer et al. (2009) proposed the VARMA-AGARCH specification for the conditional variance, namely

$$
H_{t}=W+\sum_{i=1}^{r} A_{i} \vec{\varepsilon}_{t-i}+\sum_{i=1}^{r} C_{i} I_{t-i} \vec{\varepsilon}_{t-i}+\sum_{j=1}^{s} B_{j} H_{t-j}
$$

where $C_{i}$ are $m \times m$ matrices for $i=1, . ., r$, and $I_{t}=\operatorname{diag}\left(I_{1 t}, \ldots, I_{m t}\right)$, where

$$
I_{i t}= \begin{cases}0, & \varepsilon_{i t}>0 \\ 1, & \varepsilon_{i t} \leq 0\end{cases}
$$

If $m=1$, (7) collapses to the asymmetric GARCH, or GJR model. Moreover, VARMAAGARCH reduces to VARMA-GARCH when $C_{i}=0$ for all $i$. If $C_{i}=0$ and $A_{i}$ and $B_{j}$ are diagonal matrices for all $i$ and $j$, then VARMA-AGARCH reduces to CCC. The parameters of model (5)-(8) are obtained by maximum likelihood estimation (MLE) using a joint normal density. When $\eta_{t}$ does not follow a joint multivariate normal distribution, the appropriate estimator is defined as the Quasi-MLE (QMLE).

\section{Data}

In this paper, we focus on modelling conditional volatility and examining the interdependence of the logarithm of monthly tourist arrival rate of international tourist arrivals to four leading South-East Asian countries, namely Indonesia, Malaysia, Singapore, and Thailand. The 151 monthly observations from January 1997 to July 2009 are obtained from Reuters, whereas Indonesia is obtained from Badan Pusat Statistik (BPS-Statistics, Indonesia).

Figure 3 presents the plots of the number of tourist arrivals in each country. Only three countries, namely Malaysia, Singapore and Thailand, exhibit upward trends in the number of tourist arrivals, with cyclical and seasonal patterns. Interestingly, in 2003 the numbers of 
tourist arrivals in each country collapsed because of the Severe Acute Respiratory Syndrome (hereafter SARS) epidemic. These phenomena have been affirmed by the report of the World Travel and Tourism Council (2003) that the outbreak of the SARS disease led to the collapse of the tourism industry in the most severely affected Asian countries (for an empirical analysis using panel data, see also McAleer et al. (2010)).

\section{[Insert Figure 3 here]}

Figure 4 presents the graphs of the logarithm of the monthly tourist arrival rate of the four countries. All countries show distinct seasonal patterns, but no time trend pattern exists. Surprisingly, while Singapore and Thailand display steady growth in the log monthly arrival rate, Indonesia and Malaysia exhibit greater volatility, with clustering. As in the plot of the number of tourist arrivals, SARS affected the log arrival rate significantly and negatively. Figure 5 displays the volatilities of the log arrival rate in the four countries, where volatility is calculated as the square of the estimated residuals from an ARMA(1,1) process. The plots of the volatilities in Figure 5 are similar in all four countries, with volatility clustering and an obvious outlier due to the outbreak of SARS in 2003.

\section{[Insert Figures 4 and 5 here]}

Table 3 presents the descriptive statistics for the logarithm of the monthly tourist arrival rate of four countries. The averages of the log arrival rate of the four countries are quite small and similar, while Malaysia has the largest average log arrival rate. The Jarque-Bera Lagrange Multiplier test statistics of the log arrival rate in each country are statistically significant, thereby indicating that the distributions of these log arrival rates are not normal, which may be due to the presence of extreme observations.

\section{[Insert Table 3 here]}

The unit root tests for all logarithm of the monthly tourist arrival rate are summarized in Table 4, using the EViews6 econometric software package. The Augmented Dickey-Fuller (ADF) and Phillips-Perron (PP) tests are used to test the null hypothesis of a unit root against the alternative hypothesis of stationarity. The tests provide large negative values in all cases, 
such that the individual log arrival rate series reject the null hypothesis at the $5 \%$ level, thereby indicating that all log arrival rates are stationary. These test results are supported by the KPSS test (the results are available on request).

\section{[Insert Table 4 here]}

\section{Empirical Results}

This section models the conditional volatility of the logarithm of the monthly tourist arrival rate from the four leading ASEAN tourism countries, namely Indonesia, Malaysia, Singapore and Thailand, using the CCC, VARMA-GARCH and VARMA-AGARCH models. As the univariate ARMA-GARCH model is nested in the VARMA-GARCH model, and ARMAGJR is nested in the VARMA-AGARCH model, with the conditional variances specified as in (2) and (3), the univariate ARMA-GARCH and ARMA-GJR models are also estimated.

The univariate conditional volatility models, GARCH(1,1), GJR(1,1) and EGARCH(1,1), were estimated with different mean equations. Tables 5, 6 and 7 report the estimated parameters using QMLE and the Bollerslev-Wooldridge (1992) robust $t$-ratios. The empirically satisfactory log-moment and second moment conditions were also calculated, and are available from the authors upon request.

The univariate GARCH estimates for the logarithm of the monthly tourist arrival rate are

given in Table 5. The coefficients in the mean equation are statistically significant for ARMA(1,1) for the log arrival rate series. Surprisingly, the coefficients in the variance equation are statistically significant, both in the short run and long run, only for Malaysia, and for Singapore only in the short run.

\section{[Insert Table 5 here]}

The results of two asymmetric GARCH(1,1) models, namely GJR(1,1) and EGARCH $(1,1)$, are reported in Tables 6 and 7. For GJR(1,1), only the coefficients in the mean equation for $\operatorname{AR}(1)$ are statistically significant, whereas the $\operatorname{ARMA}(1,1)$ coefficients are statistically significant only for Indonesia, Malaysia and Thailand. The estimates of the asymmetric 
effects of positive and negative shocks of equal magnitude on the conditional volatility in the GJR(1,1) model are not statistically significant, except for Indonesia and Thailand in the AR(1)-GJR(1,1) model. Therefore, the GJR model is preferred to GARCH only for Indonesia and Thailand.

\section{[Insert Table 6 here]}

For the EGARCH model in Table 7, the coefficient in the mean equation is statistically significant only for $\operatorname{ARMA}(1,1)$. The estimates of the asymmetric effects of positive and negative shocks on the conditional volatility are also not statistically significant, except for Singapore and Thailand. Therefore, the EGARCH $(1,1)$ model is preferred to GARCH only for Indonesia and Thailand.

\section{[Insert Table 7 here]}

Table 8 presents the constant conditional correlations from the CCC model, with $p=q=r=s$ $=1$, using the RATS 6.2 econometric software package. The two entries corresponding to each of the parameters are the estimate and the Bollerslev-Wooldridge (1992) robust $t$-ratios. For the four country destinations, there are six pairs of countries to be analyzed. The lowest estimated constant conditional correlation is 0.301 between Malaysia and Thailand, while the highest is 0.716 between Singapore and Thailand. This suggests that the standardized shocks in the log of the monthly tourist arrival rate for both countries are moving in the same direction. However, the CCC model does not contain any information regarding crosscountry spillover or asymmetric effects.

\section{[Insert Table 8 here]}

In order to examine the interdependent and dependent effects of volatility from one country on another, and to capture the asymmetric behaviour of the unconditional shocks on conditional volatility, the VARMA-GARCH and VARMA-AGARCH models are also estimated. The corresponding multivariate estimates of the $\operatorname{VARMA}(1,1)-\operatorname{GARCH}(1,1)$ and VARMA(1,1)-AGARCH(1,1) models for each pair of countries using the BHHH (Berndt, Hall, Hall and Hausman) algorithm, and the Bollerslev-Wooldridge (1992) robust $t$-ratios, are 
reported in Tables 9 and 10. In Table 9, the ARCH and GARCH effects are significant only for the pairs Thailand_Singapore, Singapore_Indonesia and Singapore_Malaysia, while the pairs Thailand_Malaysia and Indonesia_Malaysia have only a significant GARCH effect. In addition, volatility spillovers are found in every pair of countries, except for Thailand_Indonesia. Interestingly, a significant interdependence in the conditional volatilities between the logarithms of the monthly tourist arrival rate is evident in the pair Thailand_Singapore.

\section{[Insert Table 9 here]}

Table 10 presents the VARMA-AGARCH estimates and corresponding BollerslevWooldridge (1992) robust $t$-ratios. The ARCH and GARCH effects are significant only in the pairs Thailand_Indonesia, Singapore_Indonesia, Singapore_Malaysia and Indonesia_Malaysia, while the pair Thailand_Singapore only has a significant GARCH effect. In addition, volatility spillovers are found in all pairs of countries, except for Thailand_Indonesia and Thailand_Malaysia. Surprisingly, as in the case of VARMAGARCH, there is significant interdependence in the conditional volatilities between the logarithms of the monthly tourist arrival rate between Thailand_Singapore. As the asymmetric spillover effects for each log of the tourist rate are not statistically significant, except for Thailand_Singapore, it follows that VARMA-AGARCH is dominated by VARMA-GARCH.

\section{[Insert Table 10 here]}

\section{Concluding Remarks}

The purpose of the paper was to estimate the conditional variance, or volatility, of monthly international tourist arrivals to the four leading tourism countries in South-East Asia, namely Indonesia, Malaysia, Singapore and Thailand, and to determine the interdependence of international tourism demand of these leading ASEAN destinations, for the period January 1997 to July 2009. The modelling and econometric analysis of volatility in tourism demand can provide a useful tool for tourism organizations and government agencies concerned with travel and tourism. This is especially important for encouraging regional co-operation in 
tourism development among ASEAN member countries, and for mobilizing international and regional organizations to provide appropriate policy for the tourism industry.

This paper applied several recently developed models of multivariate conditional volatility, namely the CCC model of Bollerslev (1990), VARMA-GARCH model of Ling and McAleer (2003), and VARMA-AGARCH model of McAleer et al. (2009), to investigate the interdependence of international tourism demand, as measured by international tourist arrivals, and its associated volatility, in the leading tourism destinations. The constant conditional correlation between the log of the monthly tourist arrival rate from the CCC model were found to lie in the medium to high range. The highest conditional correlation was between the pair Thailand and Singapore, which suggests that standardized shocks in the log of the monthly tourist arrival rate of both countries are moving in the same direction.

The empirical results from the VARMA-GARCH and VARMA-AGARCH models also provided evidence of cross-country dependence in most country pairs. In addition, the results indicated that interdependent effects occur only between the pair Thailand and Singapore. However, in the conditional variance between the different countries, there is no evidence of volatility spillovers between Thailand and Indonesia. 


\section{References}

ASEAN Tourism Statistical Database 2009, available online at http://www.aseansec.org

Bollerslev, T. (1986), Generalized autoregressive conditional heteroscedasticity, Journal of Econometrices, 31, 307-327.

Bollerslev, T. (1990), Modelling the coherence in short-run nominal exchange rate: A multivariate generalized ARCH approach, Review of Economics and Statistics, 72, 498-505.

Bollerslev, T. and J. Wooldridge (1992), Quasi-maximum likelihood estimation and inference in dynamic models with time-varying covariance, Econometric Reviews, 11, 143-172.

Chan, F., C. Lim and M. McAleer (2005), Modelling multivariate international tourism demand and volatility, Tourism Management, 26(3), 459-471.

Chang C.-L., M. McAleer and C. Lim (2009a), Modelling short and long haul volatility in Japanese tourist arrivals to New Zealand and Taiwan, Working Paper CIRJE-F-647, Faculty of Economics, University of Tokyo.

Chang, C.-L., M. McAleer and D. Slottje (2009b), Modelling international tourist arrivals and volatility: An application to Taiwan, in D. Slottje (ed.), Quantifying Consumer Preferences, Contributions to Economic Analysis Series, Volume 288, Emerald Group Publishing, 2009, chapter 11, pp. 303-320.

Chang, C.-L., S. Sriboonchitta and A. Wiboonpongse (2009), Modelling and forecasting tourism from East Asia to Thailand under temporal and spatial aggregation, Mathematics and Computers in Simulation, 79, 1730-1744.

Cho, V. (2001), Tourism forecasting and its relationship with leading economic indicators, Journal of Hospitality and Tourism Research, 25, 399-420.

Cho, V. (2003), A comparison of three different approaches to tourist arrival forecasting, Tourism Management, 24(3), 323-330.

Coshall, J.T. (2005), A selection strategy for modeling UK tourism flows by air to European destinations, Tourism Economics, 11(2), 141-158.

Coshall J.T. (2009), Combining volatility and smoothing forecasts of UK demand for international tourism, Tourism Management, 30(4), 495-511.

Divino, J.A. and M. McAleer (2009a), Modelling sustainable international tourism demand to the Brazilian Amazon, Environmental Modelling and Software, 24, 1411-1419. 
Divino, J.A. and M. McAleer (2009b), Modelling and forecasting daily international mass tourism to Peru, to appear in Tourism Management.

Du Preez, J. and S.F. Witt (2003), Univariate versus multivariate time series forecasting: An application to international tourism demand, International Journal of Forecasting, 19, 435-451.

Engle, R.F. (1982). Autoregressive conditional heteroscedasticity with estimates of the variance of United Kingdom inflation. Econometrica, 50, 987-1007.

Gil-Alana, L.A. (2005), Modelling international monthly arrivals using seasonal univariate long-memory processes, Tourism Management, 26(6), 867-878.

Gil-Alana, L.A., F.P.D. Garcia and J. Cunado (2004), Seasonal fractional integration in the Spanish tourism quarterly time-series, Journal of Travel Research, 42(4), 408-414.

Glosten, L., R. Jagannathan and D. Runkle (1993), On the relation between the expected value and volatiltiy and of the nominal excess returns on stocks. Journal of Finance, 48, $1779-1801$.

Goh, C. and R. Law (2002), Modeling and forecasting tourism demand for arrivals with stochastic nonstationary seasonality and intervention, Tourism Management, 23(5), 499-510.

Hoti, S., M. McAleer and R. Shareef (2007), Modelling international tourism and country risk spillovers for Cyprus and Malta, Tourism Management, 28(6), 1472-1484.

Hylleberg, S., R.F. Engle, C.W.J. Granger and B.S, Yoo (1990), Seasonal integration and cointegration, Journal of Econometrics, 49, 215-238.

Kulendran, N. and S.F. Witt (2003a), Forecasting the demand for international business tourism, Journal of Travel Research, 41(3), 265-271.

Kulendran, N. and S.F. Witt (2003b), Leading indicator tourism forecasts, Tourism Management, 24(5), 503-510.

Kulendran, N. and K.K.F. Wong (2005), Modeling seasonality in tourism forecasting, Journal of Travel Research, 44(2), 163-170.

Lim, C. and M. McAleer (1999), A seasonal analysis of Malaysian tourist arrivals to Australia, Mathematics and Computers in Simulation, 48, 573-583.

Lim, C. and M. McAleer (2000), A seasonal analysis of Asian tourist arrivals to Australia, Applied Economics, 32(4), 499-509.

Lim, C. and M. McAleer (2001), Monthly seasonal variations: Asian tourism in Australia, Annals of Tourism Research, 28(1), 68-82. 
Lim, C. and M. McAleer (2002), Time series forecasts of international travel demand for Australia, Tourism Management, 23(4), 389-396.

Lim, C., J.C.H. Min and M. McAleer (2008), Modelling income effects on long and short haul international travel from Japan, Tourism Management, 29(6), 1099-1109.

Ling, S. and M. McAleer (2002a), Stationarity and the existence of moments of a family of GARCH processes. Journal of Econometrics, 10, 505-531

Ling, S. and M. McAleer (2002b), Necessary and sufficient moment conditions for the GARCH(r,s) and asymmetric power GARCH(r,s) models. Econometric Theory, 18, 722-729.

Ling, S. and M. McAleer (2003), Asymptotic theory for a vector ARMA-GARCH model, Econometric Theory, 19, 278-308.

McAleer, M., F. Chan and D. Marinova (2007), An econometric analysis of asymmetric volatility: Theory and application to patents, Journal of Econometrics, 139, 259-284.

McAleer, M., S. Hoti and F. Chan (2009). Structure and asymptotic theory for multivariate asymmetric conditional volatility, Econometric Reviews, 28, 422-440.

McAleer, M., B.-W. Huang, H.-I Kuo, C.-C. Chen and C.-L. Chang (2010), An econometric analysis of SARS and avian flu on international tourist arrivals to Asia, Environmental Modelling and Software, 25, 2010, 100-106.

Nelson, D.B. (1991), Conditional heteroscedasticity in asset returns: A new approach, Econometrica, 59, 347-370.

Oh, C.O. and B.J. Morzuch (2005), Evaluating time-series models to forecast the demand for tourism in Singapore: Comparing within-sample and post-sample results, Journal of Travel Research, 43(4), 404-413.

Shareef, R. and M. McAleer (2005), Modelling international tourism demand and volatility in small island tourism economies, International Journal of Tourism Research, 7, 313333.

Shareef, R. and M. McAleer (2007), Modelling the uncertainty in monthly international tourist arrivals to the Maldives, Tourism Management, 28(1), 23-45.

Shephard, N. (1996), Statistical aspects of ARCH and stochastic volatility, in O.E. BarndorffNielsen, D.R. Cox and D.V. Hinkley (eds.), Statistical Models in Econometrics, Finance and Other Fields, Chapman \& Hall, London, pp. 1-67.

Tourism Highlights (2009), The World Tourism Organization (UNWTO) publication, available online at www.unwto.org 
WTTC (2003). Singapore Special SARS Analysis Impact on Travel \& Tourism: The 2003 Travel \& Tourism Economic Research, United Kingdom, World Travel and Tourism Council. 
Table 1: International Tourist Arrivals by Region

\begin{tabular}{|c|c|c|c|c|c|c|c|c|c|c|c|}
\hline \multirow{2}{*}{ Regions } & \multicolumn{7}{|c|}{ International Tourist Arrivals (million) } & \multirow{2}{*}{$\begin{array}{c}\text { Market } \\
\text { share (\%) }\end{array}$} & \multicolumn{2}{|c|}{ Change (\%) } & \multirow{2}{*}{$\begin{array}{c}\text { Average } \\
\text { annual } \\
\text { growth (\%) }\end{array}$} \\
\hline & 1990 & 1995 & 2000 & 2005 & 2006 & 2007 & 2008 & & 07/06 & 08/07 & \\
\hline Europe & 265.0 & 309.5 & 392.6 & 441.8 & 468.4 & 487.9 & 489.4 & 53.1 & 4.1 & 0.3 & 2.8 \\
\hline Northern Europe & 28.6 & 35.8 & 43.7 & 52.8 & 56.5 & 58.1 & 57.0 & 6.2 & 2.8 & -1.9 & 3.4 \\
\hline Western Europe & 108.6 & 112.2 & 139.7 & 142.6 & 149.6 & 154.9 & 153.3 & 16.6 & 3.6 & -1.1 & 1.2 \\
\hline Central/Eastern Europe & 33.9 & 58.1 & 69.3 & 87.5 & 91.4 & 96.6 & 99.6 & 10.8 & 5.6 & 3.1 & 4.6 \\
\hline Southern/Mediter.Eu. & 93.9 & 103.4 & 139.9 & 158.9 & 170.9 & 178.2 & 179.6 & 19.5 & 4.3 & 0.8 & 3.2 \\
\hline Asia and the Pacific & 55.8 & 82.0 & 110.1 & 153.6 & 166.0 & 182.0 & 184.1 & 20.0 & 9.6 & 1.2 & 6.6 \\
\hline North-East Asia & 26.4 & 41.3 & 58.3 & 86.0 & 92.0 & 101.0 & 101.0 & 10.9 & 9.8 & -0.1 & 7.1 \\
\hline South-East Asia & 21.2 & 28.4 & 36.1 & 48.5 & 53.1 & 59.7 & 61.7 & 6.7 & 12.3 & 3.5 & 6.9 \\
\hline Ocenia & 5.2 & 8.1 & 9.6 & 11.0 & 11.0 & 11.2 & 11.1 & 1.2 & 1.7 & -0.9 & 1.8 \\
\hline South Asia & 3.2 & 4.2 & 6.1 & 8.1 & 9,8 & 10.1 & 10.3 & 1.1 & 2.6 & 2.1 & 6.8 \\
\hline Americas & 92.8 & 109.0 & 128.2 & 133.3 & 135.8 & 142.9 & 147.0 & 15.9 & 5.2 & 2.9 & 1.7 \\
\hline North America & 71.7 & 80.7 & 91.5 & 89.9 & 90.6 & 95.3 & 97.8 & 10.6 & 5.2 & 2.6 & 0.8 \\
\hline Caribbean & 11.4 & 14.0 & 17.1 & 18.8 & 19.4 & 19.8 & 20.2 & 2.2 & 1.6 & 2.0 & 2.1 \\
\hline Central America & 1.9 & 2.6 & 4.3 & 6.3 & 6.9 & 7.8 & 8.3 & 0.9 & 12.0 & 7.0 & 8.4 \\
\hline South America & 7.7 & 11.7 & 15.3 & 18.3 & 18.8 & 20.1 & 20.8 & 2.3 & 6.5 & 3.6 & 3.9 \\
\hline Africa & 15.1 & 20.0 & 27.9 & 37.3 & 41.5 & 45.0 & 46.7 & 5.1 & 8.4 & 3.7 & 6.7 \\
\hline North Africa & 8.4 & 7.3 & 10.2 & 13.9 & 15.1 & 16.3 & 17.2 & 1.9 & 8.5 & 4.9 & 6.7 \\
\hline Subsaharan Africa & 6.7 & 12.7 & 17.6 & 23.4 & 26.5 & 28.7 & 29.5 & 3.2 & 8.3 & 3.1 & 6.7 \\
\hline Middle East & 9.6 & 13.7 & 24.9 & 37.9 & 40.9 & 46.6 & 55.1 & 6.0 & 14.0 & 18.1 & 10.5 \\
\hline World & 438 & 534 & 684 & 804 & 853 & 904 & 922 & 100 & 6.1 & 2.0 & 3.8 \\
\hline
\end{tabular}

Source: World Tourism Organization (UNWTO), 2009. 
Table 2: International Tourist Arrivals to Asia and the Pacific

\begin{tabular}{|c|c|c|c|c|c|c|c|c|c|c|}
\hline \multirow{3}{*}{ Major destinations } & \multicolumn{6}{|c|}{ International Tourist Arrivals (million) } & \multicolumn{4}{|c|}{ International Tourism Receipts (\%) } \\
\hline & \multicolumn{3}{|c|}{$(1000)$} & \multicolumn{2}{|c|}{ Change (\%) } & \multirow{2}{*}{$\begin{array}{c}\text { Share }(\%) \\
2008\end{array}$} & \multicolumn{3}{|c|}{ (US\$ million) } & \multirow{2}{*}{$\begin{array}{c}\text { Share (\%) } \\
2008\end{array}$} \\
\hline & 2006 & 2007 & 2008 & $07 / 06$ & 08/07 & & 2006 & 2007 & 2008 & \\
\hline \multicolumn{11}{|l|}{ North-East Asia } \\
\hline China & 49,913 & 54,720 & 53,049 & 9.6 & -3.1 & 28.8 & 33,949 & 37,233 & 40,843 & 19.8 \\
\hline Hong Kong (China) & 15,822 & 17,154 & 17,320 & 8.4 & 1.0 & 9.4 & 11,638 & 13,754 & 15,300 & 7.4 \\
\hline Japan & 7,334 & 8,347 & 8,351 & 13.8 & 0.0 & 4.5 & 8,469 & 9,334 & 10,821 & 5.3 \\
\hline Korea, Republic of & 6,155 & 6,448 & 6,891 & 4.8 & 6.9 & 3.7 & 5,788 & 6,138 & 9,078 & 4.4 \\
\hline Macao (China) & 10,683 & 12,942 & 10,605 & 21.2 & .. & 5.8 & 9,829 & 13,612 & 13,382 & 6.5 \\
\hline Taiwan (pr.of China) & 3,520 & 3,716 & 3,845 & 5.6 & 3.5 & 2.1 & 5,136 & 5,213 & 5,937 & 2.9 \\
\hline \multicolumn{11}{|l|}{ South-East Asia } \\
\hline Cambodia & 1,591 & 1,873 & 2,001 & 17.7 & 6.8 & 1.1 & 963 & 1,135 & 1,221 & 0.6 \\
\hline Indonesia & 4,871 & 5,506 & 6,234 & 13.0 & 13.2 & 3.4 & 4,448 & 5,346 & 7,345 & 3.6 \\
\hline Lao P.D.R. & 842 & 1,142 & 1,295 & 35.6 & 13.4 & 0.7 & 173 & 233 & 276 & 0.1 \\
\hline Malaysia & 17,547 & 20,973 & 22,052 & 19.5 & 5.1 & 12.0 & 10,424 & 14,047 & 15,277 & 7.4 \\
\hline Phillippines & 2,843 & 3,092 & 3,139 & 8.7 & 1.5 & 1.7 & 3,501 & 4,931 & 4,388 & 2.1 \\
\hline Singapore & 7,588 & 7,957 & 7,778 & 4.9 & -2.2 & 4.2 & 7,535 & 9,162 & 10,575 & 5.1 \\
\hline Thailand & 13,822 & 14,464 & 14,584 & 4.6 & 0.8 & 7.9 & 13,401 & 16,669 & 17,651 & 8.6 \\
\hline Vietnam & 3,584 & 4,229 & 4,236 & 18.0 & 0.2 & 2.3 & 3,200 & 3,477 & 3,926 & 1.9 \\
\hline \multicolumn{11}{|l|}{ Ocenia } \\
\hline Australia & 5,532 & 5,644 & 5,586 & 2.0 & -1.0 & 3.0 & 17,840 & 22,298 & 24,660 & 12.0 \\
\hline New Zealand & 2,422 & 2,466 & 2,459 & 1.8 & -0.3 & 1.3 & 4,738 & 5,400 & 4,912 & 2.4 \\
\hline Fiji & 549 & 540 & 585 & -1.6 & 8.4 & 0.3 & 480 & 497 & 568 & 0.3 \\
\hline \multicolumn{11}{|l|}{ South Asia } \\
\hline India & 4,447 & 5,082 & 5,367 & 14.3 & 5.6 & 2.9 & 8,634 & 10,729 & 11,832 & 5.7 \\
\hline Maldives & 602 & 676 & 683 & 12.3 & 1.1 & 0.4 & 512 & 602 & 636 & 0.3 \\
\hline Nepal & 384 & 527 & 500 & 37.2 & -5.0 & 0.3 & 128 & 198 & 336 & 0.1 \\
\hline Pakistan & 898 & 840 & 823 & -6.6 & -2.0 & 0.5 & 255 & 276 & 245 & 0.1 \\
\hline Sri Lanka & 560 & 494 & 438 & -11.7 & -11.2 & 0.3 & 410 & 385 & 342 & 0.2 \\
\hline Asia and the Pacific & 165,989 & 181,984 & 184,104 & 9.6 & 1.2 & 100 & 157,067 & 186,789 & $\begin{array}{l}206,022 \\
\end{array}$ & 100 \\
\hline
\end{tabular}


Table 3: Descriptive Statistics

\begin{tabular}{lccccccc}
\hline Commodity & Mean & Max & Min & S.D. & Skewness & Kurtosis & Jarque-Bera \\
\hline Indonesia & 0.003 & 0.323 & -0.349 & 0.115 & -0.416 & 3.504 & 5.915 \\
Malaysia & 0.012 & 0.284 & -0.637 & 0.138 & -1.257 & 7.666 & 175.534 \\
Singapore & 0.002 & 0.577 & -0.011 & 0.141 & -1.653 & 21.740 & 2263.38 \\
Thailand & 0.004 & 0.454 & -0.608 & 0.141 & -0.509 & 5.327 & 40.331 \\
\hline
\end{tabular}


Table 4: Unit Root Tests

\begin{tabular}{|c|c|c|c|c|c|c|c|c|}
\hline \multirow{2}{*}{ Country } & \multicolumn{3}{|c|}{ Augmented Dicky-Fuller } & \multicolumn{3}{|c|}{ Phillip-Peron } & \multicolumn{2}{|c|}{ KPSS } \\
\hline & $\mathbf{N}$ & $\mathbf{C}$ & C\&T & $\mathbf{N}$ & C & C\&T & $\mathbf{C}$ & C\&T \\
\hline Indonesia & -11.660 & -11.626 & -11.610 & -16.955 & -16.952 & -17.158 & 0.102 & 0.067 \\
\hline Malaysia & -13.170 & -13.234 & -13.190 & -14.737 & -16.399 & -16.355 & 0.071 & 0.068 \\
\hline Singapore & -8.179 & -8.159 & -8.143 & -23.739 & -31.210 & -37.388 & 0.500 & 0.500 \\
\hline Thailand & -8.446 & -8.626 & -8.626 & -15.718 & -16.243 & -16.143 & 0.111 & 0.095 \\
\hline
\end{tabular}


Table 5: GARCH(1,1), AR(1)-GARCH(1,1) and ARMA(1,1)-GARCH(1,1) Estimates

\begin{tabular}{|c|c|c|c|c|c|c|c|c|}
\hline \multirow{2}{*}{ Country } & \multicolumn{3}{|c|}{ Mean equation } & \multicolumn{3}{|c|}{ Variance equation } & \multirow{2}{*}{ AIC } & \multirow{2}{*}{ SIC } \\
\hline & c & $\operatorname{AR}(1)$ & $\mathrm{MA}(1)$ & $\hat{\omega}$ & $\hat{\alpha}$ & $\hat{\beta}$ & & \\
\hline \multirow[t]{6}{*}{ Indonesia } & 0.002 & & & 0.004 & 0.107 & 0.577 & -1.463 & -1.383 \\
\hline & 0.268 & & & 0.719 & 0.941 & 1.097 & & \\
\hline & 0.003 & -0.111 & & 0.004 & 0.105 & 0.597 & -1.455 & -1.354 \\
\hline & 0.305 & -1.300 & & 0.652 & 0.923 & 1.091 & & \\
\hline & 0.001 & 0.682 & -0.983 & 0.002 & 0.077 & 0.728 & -1.566 & -1.445 \\
\hline & 1.056 & 11.01 & -91.50 & 0.575 & 0.978 & 1.781 & & \\
\hline \multirow[t]{6}{*}{ Malaysia } & 0.003 & & & 0.0004 & 0.285 & 0.769 & -1.195 & -1.115 \\
\hline & 0.228 & & & 1.457 & 3.392 & 17.96 & & \\
\hline & 0.005 & -0.309 & & 0.0002 & 0.450 & 0.713 & -1.243 & -1.142 \\
\hline & 0.612 & -2.442 & & 0.700 & 2.925 & 13.63 & & \\
\hline & 0.010 & 0.555 & -0.934 & 0.0004 & 0.485 & 0.628 & -1.243 & -1.142 \\
\hline & 10.286 & 3.544 & -31.53 & 1.496 & 2.145 & 6.374 & & \\
\hline \multirow[t]{6}{*}{ Singapore } & 0.007 & & & 0.006 & 0.166 & 0.511 & -1.171 & -1.090 \\
\hline & 0.899 & & & 2.275 & 1.721 & 3.477 & & \\
\hline & 0.017 & -0.254 & & 0.009 & 0.849 & 0.017 & -1.209 & -1.108 \\
\hline & 1.960 & -2.921 & & 4.610 & 0.907 & 0.125 & & \\
\hline & 0.016 & -0.576 & 0.891 & 0.005 & 0.791 & 0.063 & -1.460 & -1.339 \\
\hline & 1.818 & -7.347 & 37.91 & 3.265 & 2.199 & 0.621 & & \\
\hline \multirow[t]{6}{*}{ Thailand } & -0.002 & & & 0.009 & 0.227 & 0.295 & -1.112 & -1.032 \\
\hline & -0.181 & & & 1.178 & 1.175 & 0.625 & & \\
\hline & -0.004 & 0.102 & & 0.008 & 0.227 & 0.369 & -1.108 & -1.008 \\
\hline & -0.380 & 0.970 & & 1.290 & 1.206 & 0.955 & & \\
\hline & -0.005 & -0.451 & 0.737 & 0.007 & 0.266 & 0.332 & -1.187 & -1.067 \\
\hline & -0.396 & -2.700 & 6.021 & 1.665 & 1.306 & 1.077 & & \\
\hline
\end{tabular}

Note: The two entries for each parameter are their respective parameter estimate and Bollerslev and Wooldridge (1992) robust $t$ - ratios. Entries in bold are significant at the $5 \%$ level. 
Table 6: GJR(1,1), AR(1)-GJR(1,1) and ARMA(1,1)-GJR(1,1) Estimates

\begin{tabular}{|c|c|c|c|c|c|c|c|c|c|}
\hline \multirow{2}{*}{ Country } & \multicolumn{3}{|c|}{ Mean equation } & \multicolumn{4}{|c|}{ Variance equation } & \multirow{2}{*}{ AIC } & \multirow{2}{*}{ SIC } \\
\hline & C & $\mathrm{AR}(1)$ & MA(1) & $\hat{\omega}$ & $\hat{\alpha}$ & $\hat{\gamma}$ & $\hat{\beta}$ & & \\
\hline \multirow[t]{6}{*}{ Indonesia } & -0.004 & & & 0.002 & -0.063 & 0.247 & 0.766 & -1.469 & $\begin{array}{c}-1.369 \\
\end{array}$ \\
\hline & -0.455 & & & 0.965 & -0.336 & 1.456 & 2.769 & & \\
\hline & -0.011 & -0.211 & & 0.001 & -0.183 & 0.309 & 0.996 & -1.469 & -1.369 \\
\hline & -1.777 & -3.428 & & 4.278 & -9.534 & 12.32 & 48.31 & & \\
\hline & 0.001 & 0.672 & -0.984 & 0.020 & 0.132 & -0.087 & -0.859 & & \\
\hline & 1.586 & 11.25 & -106.1 & 4.452 & 1.194 & -0.706 & -4.514 & & \\
\hline \multirow[t]{6}{*}{ Malaysia } & 0.004 & & & 0.011 & -0.030 & 0.587 & 0.182 & -1.153 & -1.053 \\
\hline & 0.356 & & & 2.301 & -0.211 & 1.413 & 1.359 & & \\
\hline & 0.008 & -0.206 & & 0.012 & -0.098 & 0.686 & 0.174 & -1.160 & -1.039 \\
\hline & 0.842 & -2.559 & & 2.714 & -1.094 & 1.437 & 1.508 & & \\
\hline & 0.010 & 0.579 & -0.945 & 0.0005 & 0.607 & -0.270 & 0.636 & -1.375 & -1.233 \\
\hline & 9.412 & 4.309 & -30.83 & 1.477 & 2.271 & -0.943 & 5.289 & & \\
\hline \multirow[t]{6}{*}{ Singapore } & -0.009 & & & 0.006 & -0.122 & 2.310 & 0.278 & -1.321 & -1.220 \\
\hline & -1.244 & & & 6.567 & -1.812 & 1.156 & 2.532 & & \\
\hline & -0.016 & -0.252 & & 0.006 & -0.250 & 2.030 & 0.416 & -1.374 & -1.253 \\
\hline & -2.434 & -5.281 & & 3.654 & -5.734 & 0.900 & 1.933 & & \\
\hline & -0.003 & 0.200 & -0.582 & 0.004 & -0.210 & 1.729 & 0.440 & -1.468 & -1.327 \\
\hline & -0.554 & 1.840 & -8.628 & 4.592 & -3.371 & 0.907 & 2.552 & & \\
\hline \multirow[t]{6}{*}{ Thailand } & -0.016 & & & 0.003 & -0.210 & 0.554 & 0.828 & -1.158 & -1.057 \\
\hline & -1.596 & & & 1.357 & -2.870 & 2.071 & 5.978 & & \\
\hline & -0.018 & 0.196 & & 0.006 & -0.178 & 0.612 & 0.577 & -1.157 & -1.036 \\
\hline & -1.247 & 3.200 & & 2.543 & -2.829 & 2.074 & 4.055 & & \\
\hline & -0.011 & -0.410 & 0.679 & 0.006 & -0.149 & 0.430 & 0.572 & -1.241 & -1.100 \\
\hline & -0.843 & -2.604 & 4.120 & 2.005 & -2.001 & 1.481 & 3.010 & & \\
\hline
\end{tabular}

Note: The two entries for each parameter are their respective parameter estimate and Bollerslev and Wooldridge (1992) robust $t$ - ratios. Entries in bold are significant at the 5\% level. 
Table 7: EGARCH(1,1), AR(1)- EGARCH(1,1) and ARMA(1,1)- EGARCH(1,1) Estimates

\begin{tabular}{|c|c|c|c|c|c|c|c|c|c|}
\hline \multirow{2}{*}{ Country } & \multicolumn{3}{|c|}{ Mean equation } & \multicolumn{4}{|c|}{ Variance equation } & \multirow{2}{*}{ AIC } & \multirow{2}{*}{ SIC } \\
\hline & c & $\mathrm{AR}(1)$ & MA(1) & $\hat{\omega}$ & $\hat{\alpha}$ & $\hat{\gamma}$ & $\hat{\beta}$ & & \\
\hline \multirow[t]{6}{*}{ Indonesia } & 0.004 & & & -6.425 & 0.136 & 0.191 & -0.448 & -1.457 & -1.356 \\
\hline & 0.495 & & & -3.215 & 0.727 & 1.565 & -1.027 & & \\
\hline & 0.003 & -0.047 & & -6.520 & 0.107 & 0.174 & -0.477 & -1.440 & -1.319 \\
\hline & 0.357 & -0.559 & & -2.958 & 0.551 & 1.420 & -0.985 & & \\
\hline & 0.001 & 0.641 & -0.983 & -8.147 & 0.298 & -0.012 & -0.752 & -1.580 & -1.439 \\
\hline & 1.647 & 10.27 & -85.76 & -16.45 & 2.623 & -0.143 & -6.325 & & \\
\hline \multirow[t]{6}{*}{ Malaysia } & 0.012 & & & -0.307 & 0.302 & 0.135 & 0.978 & -1.213 & -1.112 \\
\hline & 1.298 & & & -1.779 & 4.810 & 0.498 & 28.03 & & \\
\hline & 0.012 & -0.139 & & -2.726 & 0.061 & -0.305 & 0.336 & -1.124 & -1.003 \\
\hline & 1.266 & -1.524 & & -1.369 & 0.270 & -2.085 & 0.619 & & \\
\hline & 0.011 & -0.938 & 0.984 & -0.362 & 0.316 & 0.014 & 0.973 & -1.283 & -1.142 \\
\hline & 1.315 & -22.90 & 65.14 & -2.812 & 4.841 & 0.094 & 42.34 & & \\
\hline \multirow[t]{6}{*}{ Singapore } & -0.029 & & & -0.217 & -0.177 & -0.560 & 0.896 & -1.465 & -1.365 \\
\hline & -3.180 & & & -0.735 & -0.842 & -2.040 & 36.43 & & \\
\hline & -0.026 & -0.050 & & -0.130 & -0.188 & -0.556 & 0.919 & -1.445 & -1.324 \\
\hline & -2.603 & -0.597 & & -1.413 & -1.492 & -2.458 & 51.79 & & \\
\hline & 0.003 & 0.495 & -0.990 & -7.225 & 0.185 & -0.668 & -0.482 & -1.822 & -1.681 \\
\hline & 10.54 & 9.964 & -333.8 & -14.35 & 0.757 & -3.545 & -4.632 & & \\
\hline \multirow[t]{6}{*}{ Thailand } & -0.017 & & & -0.235 & -0.001 & -0.382 & 0.934 & -1.150 & -1.049 \\
\hline & -1.705 & & & -0.687 & -0.009 & -2.714 & 12.04 & & \\
\hline & -0.023 & 0.116 & & -0.428 & 0.076 & -0.344 & 0.901 & -1.143 & -1.022 \\
\hline & -1.739 & 1.259 & & -0.787 & 0.581 & -2.543 & 7.619 & & \\
\hline & -0.018 & -0.392 & 0.663 & -0.269 & 0.044 & -0.292 & 0.937 & -1.192 & -1.051 \\
\hline & -1.459 & -1.950 & 3.782 & -0.644 & 0.348 & -2.144 & 10.53 & & \\
\hline
\end{tabular}

Note: The two entries for each parameter are their respective parameter estimate and Bollerslev and Wooldridge (1992) robust $t$ - ratios. Entries in bold are significant at the 5\% level. 
Table 8: Constant Conditional Correlations

\begin{tabular}{|c|c|c|c|c|c|c|c|}
\hline Country & Indonesia & t-ratio & Malaysia & t-ratio & Singapore & t-ratio & Thailand \\
\hline Indonesia & 1 & & & & & & \\
\hline Malaysia & 0.318 & (3.429) & 1 & & & & \\
\hline Singapore & 0.534 & (6.420) & 0.405 & (3.468) & 1 & & \\
\hline Thailand & 0.455 & (5.062) & 0.301 & (3.389) & 0.716 & (11.195) & 1 \\
\hline
\end{tabular}

Note: The two entries for each parameter are their respective parameter estimate and Bollerslev and Wooldridge (1992) robust $t$ - ratios. Entries in bold are significant at the 5\% level. 
Table 9: VARMA-GARCH Estimates

\begin{tabular}{|c|c|c|c|c|c|}
\hline \multicolumn{6}{|c|}{ Panel 9a Thailand_Indonesia } \\
\hline Country & $\omega$ & $\alpha_{\text {Thai }}$ & $\alpha_{\text {Indo }}$ & $\beta_{\text {Thai }}$ & $\beta_{\text {Indo }}$ \\
\hline \multirow[t]{2}{*}{ Thailand } & -0.008 & 0.184 & -0.017 & 0.191 & 1.489 \\
\hline & -0.941 & 1.065 & -0.125 & 0.494 & 1.619 \\
\hline \multirow[t]{2}{*}{ Indonesia } & 0.005 & 0.088 & 0.096 & -0.224 & 0.753 \\
\hline & 2.261 & 1.271 & 1.026 & -0.863 & 1.828 \\
\hline \multicolumn{6}{|c|}{ Panel 9b Thailand_Malaysia } \\
\hline Country & $\omega$ & $\alpha_{\text {Thai }}$ & $\alpha_{\text {Malay }}$ & $\beta_{\text {Thai }}$ & $\beta_{\text {Malay }}$ \\
\hline \multirow[t]{2}{*}{ Thailand } & 0.007 & 0.266 & 0.015 & 0.336 & -0.012 \\
\hline & 1.724 & 1.346 & 0.441 & 1.125 & -0.391 \\
\hline \multirow[t]{2}{*}{ Malaysia } & 0.016 & 0.418 & 0.072 & -1.215 & 0.907 \\
\hline & 2.402 & 2.034 & 1.455 & -2.289 & 12.84 \\
\hline \multicolumn{6}{|c|}{ Panel 9c Thailand_Singapore } \\
\hline Country & $\omega$ & $\alpha_{\text {Thai }}$ & $\alpha_{\text {Sing }}$ & $\beta_{\text {Thai }}$ & $\beta_{\text {Sing }}$ \\
\hline \multirow[t]{2}{*}{ Thailand } & 0.012 & 0.535 & -0.129 & -0.069 & 0.115 \\
\hline & 3.137 & 2.483 & -2.740 & -0.401 & 2.573 \\
\hline \multirow[t]{2}{*}{ Singapore } & 0.020 & 0.312 & 0.064 & -1.404 & 1.014 \\
\hline & 320.4 & 3.641 & 2.191 & -35.73 & 17.04 \\
\hline \multicolumn{6}{|c|}{ Panel 9d Singapore_Indonesia } \\
\hline Country & $\omega$ & $\alpha_{\text {Sing }}$ & $\alpha_{\text {Indo }}$ & $\beta_{\text {Sing }}$ & $\beta_{\text {Indo }}$ \\
\hline \multirow[t]{2}{*}{ Singapore } & -0.001 & 0.631 & -0.019 & 0.088 & 0.630 \\
\hline & -0.222 & 1.305 & -0.154 & 0.432 & 1.179 \\
\hline \multirow[t]{2}{*}{ Indonesia } & 0.012 & 0.244 & 0.133 & 0.198 & -0.762 \\
\hline & 4.672 & 2.472 & 2.657 & 3.006 & -14.95 \\
\hline \multicolumn{6}{|c|}{ Panel 9e Singapore_Malaysia } \\
\hline Country & $\omega$ & $\alpha_{\text {Sing }}$ & $\alpha_{\text {Malay }}$ & $\beta_{\text {Sing }}$ & $\beta_{\text {Malay }}$ \\
\hline \multirow[t]{2}{*}{ Singapore } & 0.009 & 0.315 & 0.345 & 0.413 & -0.150 \\
\hline & 4.388 & 1.496 & 1.695 & 2.339 & -2.650 \\
\hline \multirow[t]{2}{*}{ Malaysia } & 0.003 & -0.059 & 0.136 & 0.022 & 0.833 \\
\hline & 1.443 & -2.746 & 2.161 & 1.835 & 8.547 \\
\hline \multicolumn{6}{|c|}{ Panel 9f Indonesia_Malaysia } \\
\hline Country & $\omega$ & $\alpha_{\text {Indo }}$ & $\alpha_{\text {Malay }}$ & $\beta_{\text {Indo }}$ & $\beta_{\text {Malay }}$ \\
\hline \multirow[t]{2}{*}{ Indonesia } & 0.002 & 0.075 & -0.011 & 0.750 & -0.001 \\
\hline & 0.648 & 0.999 & -0.681 & 2.114 & -0.065 \\
\hline \multirow[t]{2}{*}{ Malaysia } & 0.002 & -0.247 & 0.033 & 0.395 & 0.836 \\
\hline & 0.113 & -5.112 & 1.136 & 0.625 & 3.318 \\
\hline
\end{tabular}

Note: The two entries for each parameter are their respective parameter estimate and Bollerslev and Wooldridge (1992) robust $t$ - ratios. Entries in bold are significant at the 5\% level. 
Table 10: VARMA-AGARCH Estimates

\begin{tabular}{|c|c|c|c|c|c|c|}
\hline \multicolumn{7}{|c|}{ Panel 10a Thailand_Indonesia } \\
\hline Country & $\omega$ & $\alpha_{\text {Thai }}$ & $\alpha_{\text {Indo }}$ & $\gamma$ & $\beta_{\text {Thai }}$ & $\beta_{\text {Indo }}$ \\
\hline \multirow[t]{2}{*}{ Thailand } & -0.005 & -0.144 & 0.069 & 0.635 & 0.303 & 1.158 \\
\hline & -0.855 & -2.480 & 0.562 & 2.222 & 1.508 & 1.740 \\
\hline \multirow[t]{2}{*}{ Indonesia } & 0.001 & 0.040 & -0.195 & 0.257 & -0.046 & 0.975 \\
\hline & 0.634 & 1.101 & -2.746 & 1.740 & -0.361 & 16.61 \\
\hline \multicolumn{7}{|c|}{ Panel 10b Thailand_Malaysia } \\
\hline Country & $\omega$ & $\alpha_{\text {Thai }}$ & $\alpha_{\text {Malay }}$ & $\gamma$ & $\beta_{\text {Thai }}$ & $\beta_{\text {Malay }}$ \\
\hline \multirow[t]{2}{*}{ Thailand } & 0.008 & -0.126 & 0.039 & 0.562 & 0.374 & 0.012 \\
\hline & 2.095 & -1.882 & 0.858 & 1.862 & 1.329 & 0.416 \\
\hline \multirow[t]{2}{*}{ Malaysia } & 0.004 & 0.193 & -0.112 & 0.898 & 0.730 & -0.074 \\
\hline & 0.422 & 1.238 & -1.542 & 1.647 & 1.125 & -0.835 \\
\hline \multicolumn{7}{|c|}{ Panel 10c Thailand_Singapore } \\
\hline Country & $\omega$ & $\alpha_{\text {Thai }}$ & $\alpha_{\text {Sing }}$ & $\gamma$ & $\beta_{\text {Thai }}$ & $\beta_{\text {Sing }}$ \\
\hline \multirow[t]{2}{*}{ Thailand } & 0.009 & -0.036 & -0.172 & -0.722 & -0.039 & 0.409 \\
\hline & 2.509 & -0.722 & -2.595 & 2.480 & -0.190 & 3.661 \\
\hline \multirow[t]{2}{*}{ Singapore } & 0.017 & 0.157 & -0.155 & 0.385 & -1.044 & 0.972 \\
\hline & $\mathbf{0 . 0 1 7}$ & 2.716 & -1.459 & 2.472 & -1.044 & 19.63 \\
\hline \multicolumn{7}{|c|}{ Panel 10d Singapore_Indonesia } \\
\hline Country & $\omega$ & $\alpha_{\text {Sing }}$ & $\alpha_{\text {Indo }}$ & $\gamma$ & $\beta_{\text {Sing }}$ & $\beta_{\text {Indo }}$ \\
\hline \multirow[t]{2}{*}{ Singapore } & 0.016 & 0.164 & 0.110 & 1.228 & 0.132 & -0.934 \\
\hline & 5.086 & 1.781 & 1.461 & 1.378 & 1.783 & -4.728 \\
\hline \multirow[t]{2}{*}{ Indonesia } & 0.001 & 0.012 & -0.178 & -2.565 & -0.008 & 0.999 \\
\hline & 1.915 & 0.430 & -2.565 & 1.690 & -0.260 & 25.02 \\
\hline \multicolumn{7}{|c|}{ Panel 10e Singapore_Malaysia } \\
\hline Country & $\omega$ & $\alpha_{\text {Sing }}$ & $\alpha_{\text {Malay }}$ & $\gamma$ & $\beta_{\text {Sing }}$ & $\beta_{\text {Malay }}$ \\
\hline \multirow[t]{2}{*}{ Singapore } & 0.006 & -0.149 & 0.089 & 1.307 & 0.369 & -0.045 \\
\hline & 5.927 & -2.374 & 1.449 & 1.297 & 2.831 & -2.424 \\
\hline \multirow[t]{2}{*}{ Malaysia } & 0.021 & -0.035 & -0.285 & 0.913 & -0.030 & 0.150 \\
\hline & 5.174 & -5.033 & -5.581 & 1.840 & -2.974 & 1.440 \\
\hline \multicolumn{7}{|c|}{ Panel 10f Indonesia_Malaysia } \\
\hline Country & $\omega$ & $\alpha_{\text {Indo }}$ & $\alpha_{\text {Malay }}$ & $\gamma$ & $\beta_{\text {Indo }}$ & $\beta_{\text {Malay }}$ \\
\hline \multirow[t]{2}{*}{ Indonesia } & 0.002 & -0.149 & -0.031 & 0.322 & 0.891 & 0.013 \\
\hline & 2.107 & -1.809 & -1.267 & 2.834 & 12.031 & 0.611 \\
\hline \multirow[t]{2}{*}{ Malaysia } & 0.038 & -0.194 & -0.324 & 0.838 & -1.067 & 0.223 \\
\hline & 4.062 & -3.071 & -5.352 & 1.997 & -2.207 & 1.816 \\
\hline
\end{tabular}

Note: The two entries for each parameter are their respective parameter estimate and Bollerslev and Wooldridge (1992) robust $t$ - ratios. Entries in bold are significant at the 5\% level. 
Figure 1

Tourist Arrivals to ASEAN by Source

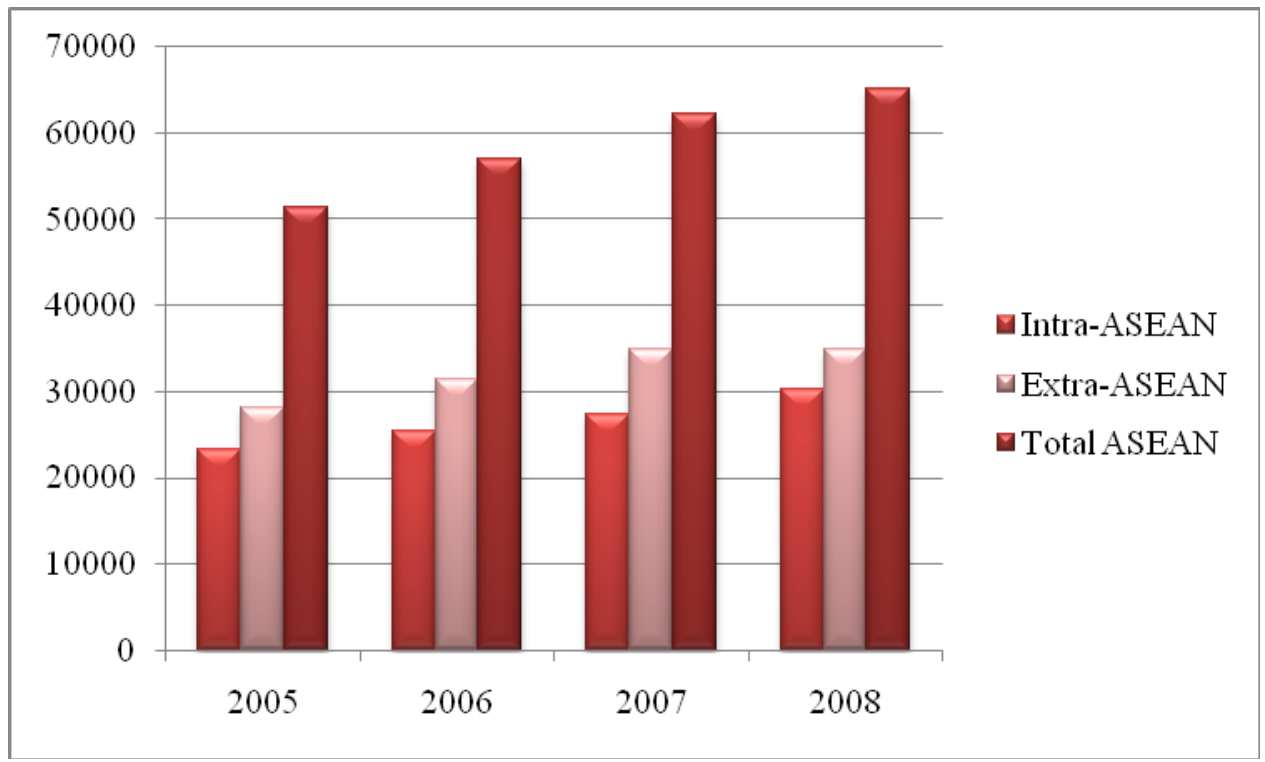

Source: ASEAN Tourism Statistical Database 2009. 
Figure 2

\section{Tourist Arrivals to ASEAN by Country and Source}

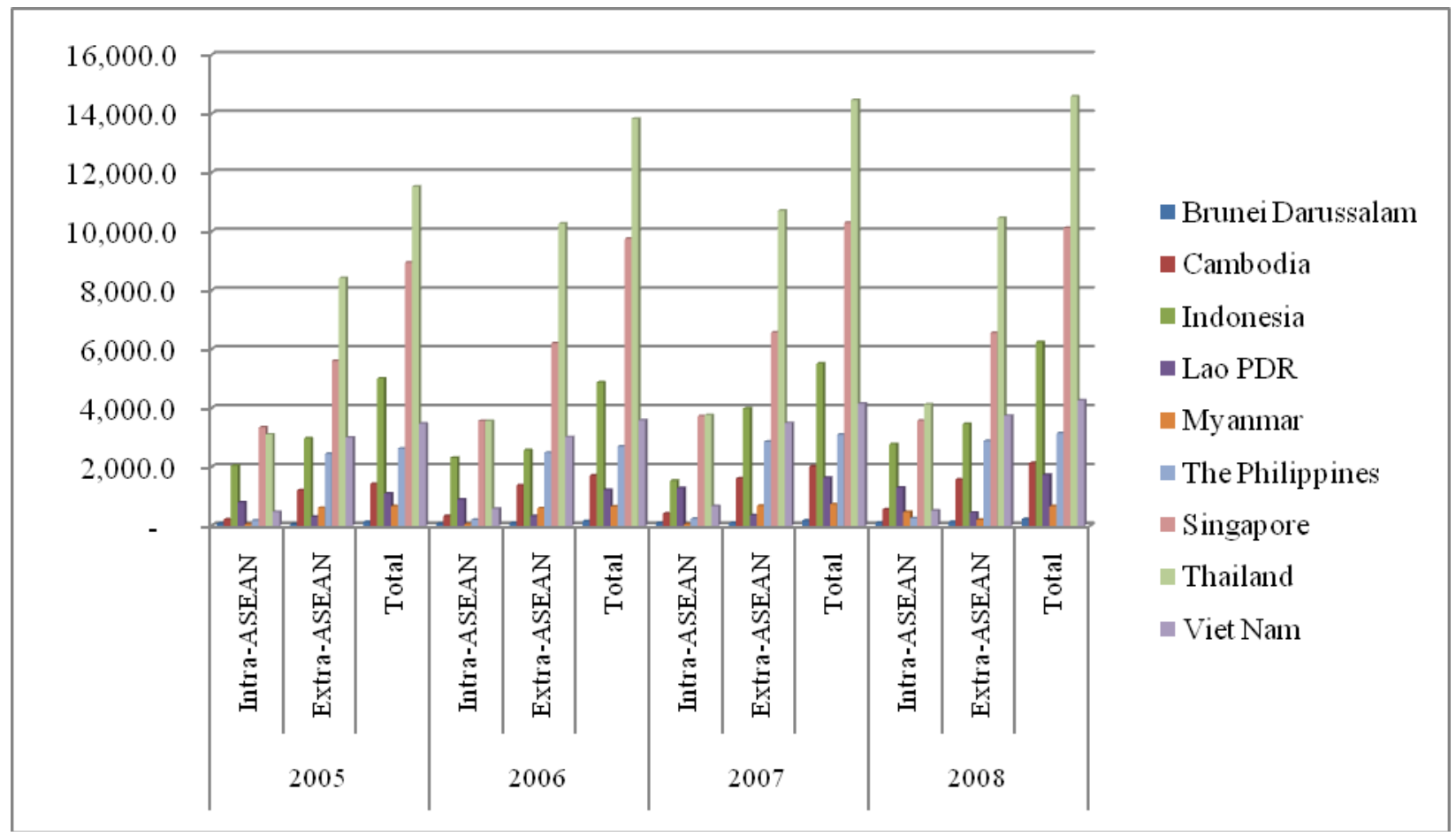

Source: ASEAN Tourism Statistical Database 2009. 
Figure 3

\section{Tourist Arrivals in ASEAN}
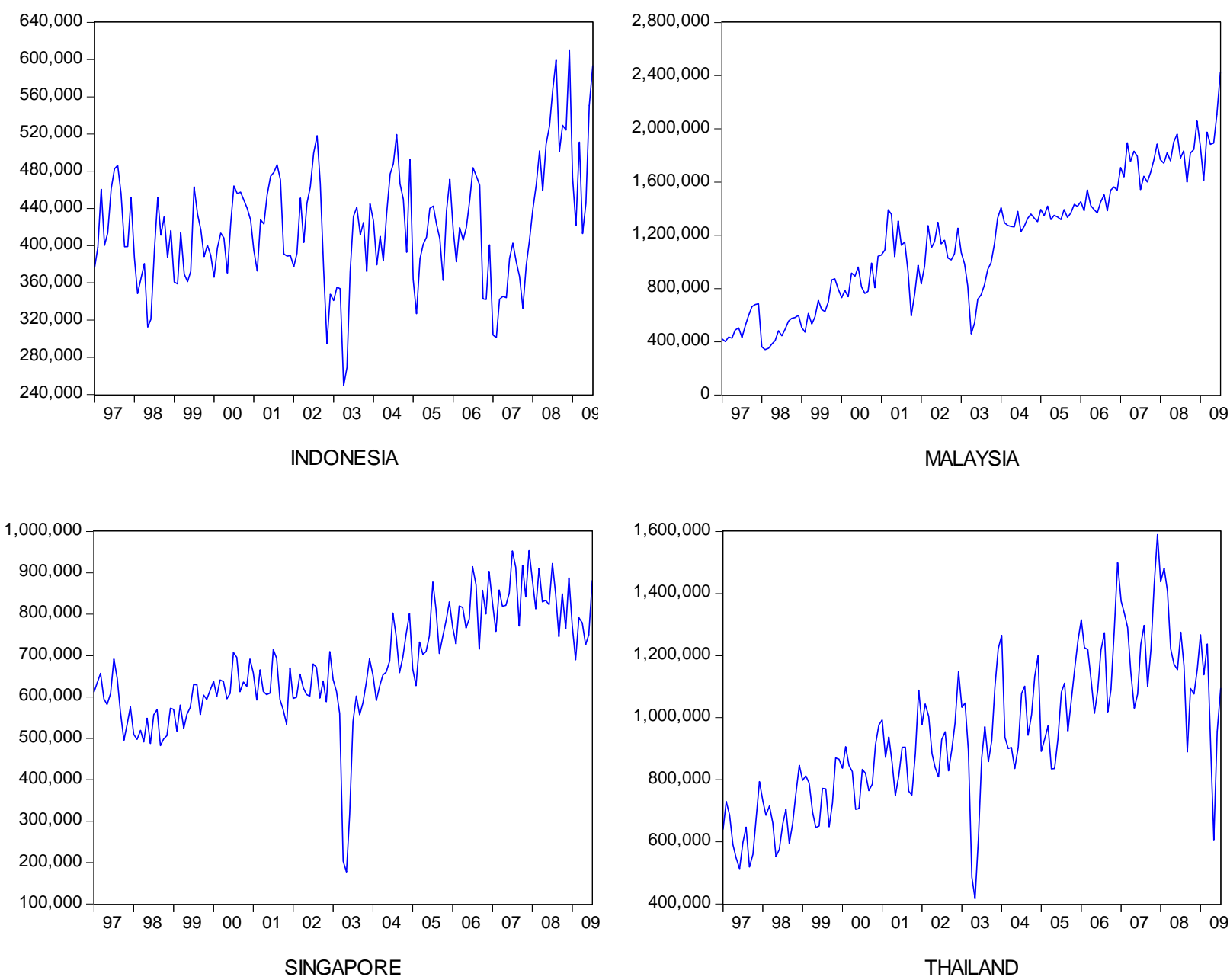
Figure 4

\section{Log Arrival Rate of Leading Four Countries}
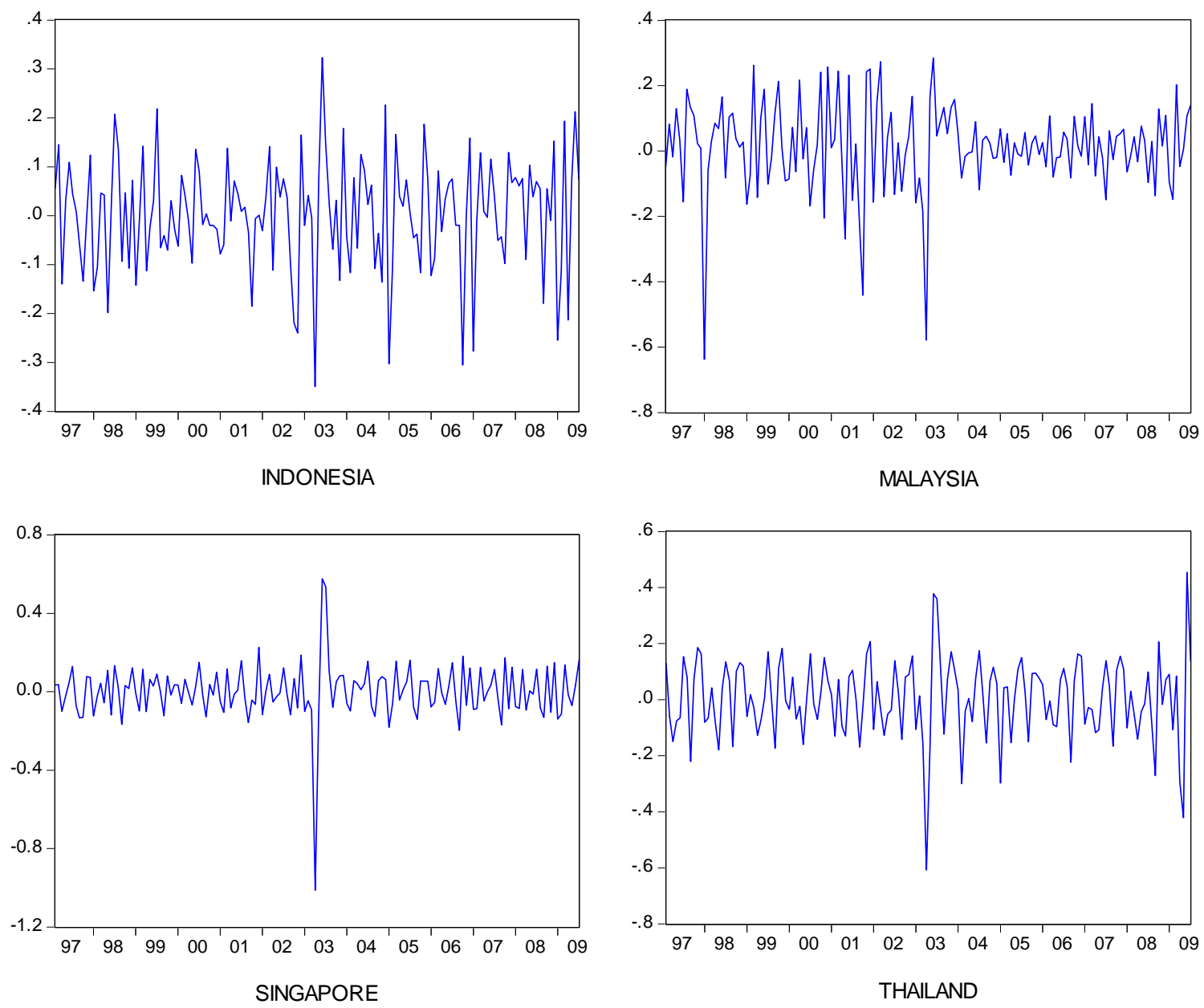
Figure 5

\section{Volatility of Log Arrival Rate of Leading Four Countries.}
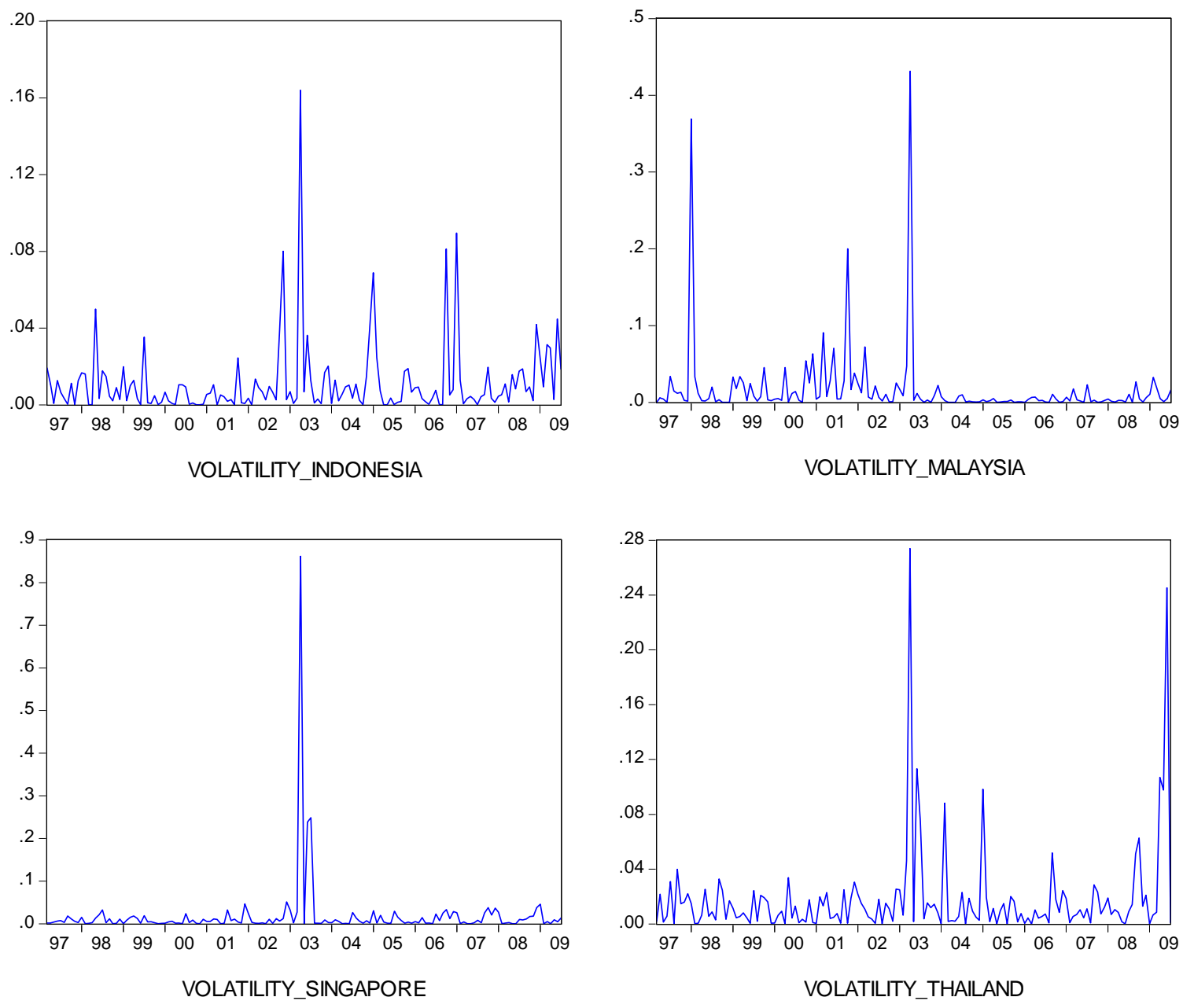